\title{
The Use of Anti-Septic Solutions in the Prevention of Neurosurgical Site Infections
}

\author{
Samuel Kalb ${ }^{1}$, Richard D Lefevre ${ }^{1}$, Marina Dididze ${ }^{2}$ and Allan D Levi ${ }^{2 *}$
}

${ }^{1}$ Division of Neurological Surgery, Barrow Neurological Institute, St. Joseph's Hospital and Medical Center, Phoenix, Arizona, USA

${ }^{2}$ Department of Neurological Surgery and The Miami Project to Cure Paralysis, University of Miami MILLER School of Medicine, Miami, Florida, USA

\begin{abstract}
Object: Pre-incisional skin preparation with an antiseptic solution is crucial in preventing SSI. However, a lack of consensus in both general and spine surgery regarding the preference of skin preparation methods continues. The goal of this study is to evaluate the preferred method of pre-operative skin preparation for spine surgery in various academic and non-academic institutions in the United States.

Methods: The study data were generated from a telephone survey that emphasized the type of preoperative antiseptic solution used in spinal surgery. The options were: Betadine (povidone-iodine), DuraPrep (iodine-povacrylex and isopropyl alcohol), ChloraPrep ( $2 \%$ chlorhexidine and $70 \%$ isopropyl alcohol), and any possible combinations. A total of 128 neurosurgical departments across the United States were contacted, including all 98 ACGME accredited neurosurgical programs. Results were reported on the basis of type antiseptic solution used by each institution and by geographical region based on United States census regional distribution.

Results: Most of the neurosurgical centers used DuraPrep followed by ChloraPrep and then Betadine. Thirtyseven centers used various combinations either as a preference in isolated cases or as a combination. The surveyed neurosurgical departments came from all 9 regions in the United States (Pacific, Mountain, West south central, West north central, East north central, East south central, South Atlantic, Middle Atlantic, and New England. ChloraPrep is the preferred choice in 5 regions, whereas DuraPrep is preferred in the other 3 regions
\end{abstract}

Conclusions: Although most of the literature is in favor of ChloraPrep over Betadine or DuraPrep in reducing $\mathrm{SSI}$, the majority of neurosurgical departments continue to use iodine solutions in spine procedures.

Keywords: Spine; Anti-septic solutions; Surgical site infection; Preoperative preparation; Iodine chlorhexidine

\section{Introduction}

The incidence of surgical site infection (SSI) varies from 0.7 to $11.9 \%$ after spinal surgical procedures [1-4]. Pre-incisional skin preparation with an antiseptic solution is crucial in preventing SSI. ChloraPrep (2\% chlorhexidine and $70 \%$ isopropyl alcohol; CareFusion, Inc., Leawood, KS) and DuraPrep ${ }^{\mathrm{TM}}$ (iodine-povacrylex and isopropyl alcohol; Surgical Solution, 3M Health Care, St. Paul, $\mathrm{MN}$ ) are among several alcohol based skin preparations approved by the U.S. Food and Drug Administration for use prior to surgery and have become increasingly popular over the last 2 decades amongst spine surgeons. Iodine has been recognized for its ability to prevent skin infections since its discovery in 1811. Betadine (Microbicides, Purdue Products L.P., Stamford, CT) is a brand name for a range of povidone-iodine topical antiseptics that have been in use in the operating room for over half a century.

Two recent meta-analyses reported that the use of chlorhexidine significantly decreased the risk of SSI compared with iodine in general surgical procedures and related specialties [5-6]. However, almost at the same time, a Swenson et al study reported lower SSI rates in general surgical procedures with the use of povidone-iodine preparation compared to chlorhexidine [7]. Therefore, a lack of consensus in both general and spine surgery regarding the preference of skin preparation methods continues.

The aim of our study is to evaluate the preferred method of preoperative skin preparation for spine surgery in various academic and non-academic institutions in the United States through a simple telephone survey.

\section{Material and Methods}

The study data were generated from a telephone survey, which covered aspects of institutional and personal neurosurgical experience. Only neurosurgical departments were contacted, and in all cases a member of the neurosurgical faculty was contacted and questioned. The name of the contacted faculty member was not registered, and the questions were asked under those pretences. The survey included one simple question that emphasized the type of preoperative antiseptic solution used in spinal surgery. The options were: a) Betadine, b) DuraPrep, c) ChloraPrep, and any possible combinations.

The institutional names and telephone numbers were obtained from the 2011 U.S. News and World Report. First time non-responders were re-contacted several times until data was collected. A total of 128 neurosurgical departments across the United States (including Puerto Rico) were contacted, including all 98 ACGME accredited neurosurgical programs.

Results were reported on the basis of type antiseptic solution used by each institution and by geographical region based on United

*Corresponding author: Allan D Levi, Department of Neurological Surgery and The Miami Project to Cure Paralysis, University of Miami, MILLER School of Medicine, Miami, Florida, USA, E-mail: ALevi@med.miami.edu

Received June 13, 2013; Accepted July 29, 2013; Published August 04, 2013

Citation: Kalb S, Lefevre RD, Dididze M, Levi AD (2013) The Use of Anti-Septic Solutions in the Prevention of Neurosurgical Site Infections. Clin Microbial 2: 124. doi: 10.4172/2327-5073.1000124

Copyright: (c) 2013 Kalb S, et al. This is an open-access article distributed under the terms of the Creative Commons Attribution License, which permits unrestricted use, distribution, and reproduction in any medium, provided the original author and source are credited. 
Citation: Kalb S, Lefevre RD, Dididze M, Levi AD (2013) The Use of Anti-Septic Solutions in the Prevention of Neurosurgical Site Infections. Clin Microbial 2: 124. doi: 10.4172/2327-5073.1000124

Page 2 of 5

States census regional distribution [7]. For data analysis, answers were entered onto a Microsoft Excel spreadsheet. The results are presented in percentage.

\section{Results}

Within 2 months, one hundred twenty six responses were obtained, which was a response rate of $98.4 \%$. Two programs did not respond after numerous attempts at contact. The analysis revealed that most of the centers ( $n=73,57.93 \%)$ overall preferred the use of DuraPrep (iodine povacrylex and isopropyl alcohol) followed by ChloraPrep $(\mathrm{n}=68,53.96 \%)$ and then Betadine $(\mathrm{n}=49,38.88 \%)$. Some centers $(n=37,29.36 \%)$ used different types of solutions either as a preference in isolated cases or as a combination, using 2 or more agents in the same case. Within the centers surveyed regarding skin preparation preference that commonly use more than one type of solution: $3(8.10 \%)$ used DuraPrep and/or ChloraPrep ; $11(29.72 \%)$ used DuraPrep and/or Betadine; and 23 (62.16\%) would potentially use all three in isolation or combination. No centers used both ChloraPrep and Betadine (Figure 1 and Figure 2).

The surveyed neurosurgical departments, including all 98 ACGME accredited programs, came from all 9 regions in the United States as determined by the US Department of Commerce, Economics and Statistics Administration, U.S. Census Bureau and, Prepared by the Geography Division, 2011 (Table 1). The surveyed neurosurgical programs came from the Pacific $(n=13,10.3 \%)$, Mountain $(n=4,3.17 \%)$, West south central $(n=9,7.14 \%)$, West north central $(n=11,8.73 \%)$, East north central $(n=33,26.19 \%)$, East south central $(n=8,6.34 \%)$, South Atlantic $(n=19,15.07 \%)$, Middle Atlantic $(n=20,15.87 \%)$, and

Preoperative Antiseptic Use Among Neurosurgical Programs, 2012

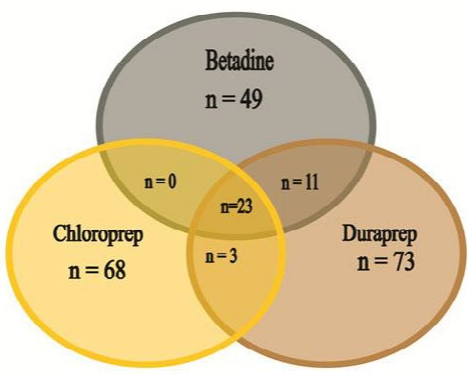

Figure 1: Venn Diagram of Preopereative Antiseptic use among Neurosurgical Programs surveyed in 2012.

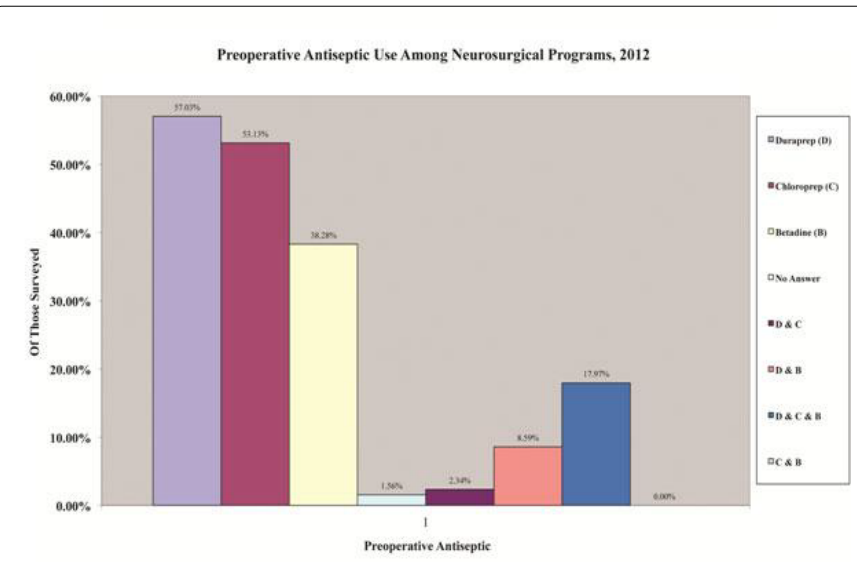

Figure 2: Preoperative Antiseptic use among Neurosurgical Programs, 2012.

\section{Pacific:}

Alaska, California, Hawaii, Oregon, Washington

Mountain:

Arizona, Colorado, Idaho, Montana, Nevada, Utah, Wyoming

West South Central:

Arkansas, Oklahoma, Louisiana, Texas

West North Central:

lowa, Kansas, Minnesota, Missouri, Nebraska, North Dakota, South Dakota

\section{East North Central:}

Ohio, Illinois, Indiana, Michigan, Wisconsin

East South Central:

Alabama, Kentucky, Mississippi, Tennessee

South Atlantic:

Delaware, Florida, Georgia, Maryland, North Carolina, South Carolina, Virginia, Washington D.C., West Virginia

Middle Atlantic:

New Jersey, New York, Pennsylvania

New England:

Connecticut, Maine, Massachusetts, New Hampshire, Rhode Island, Vermont

Information obtained from the US Department of Commerce, Economics and Statistics Administration, U.S. Census Bureau and, Prepared by the Geography Division, 2011

Table 1: Census Regions and Divisions of the United States.

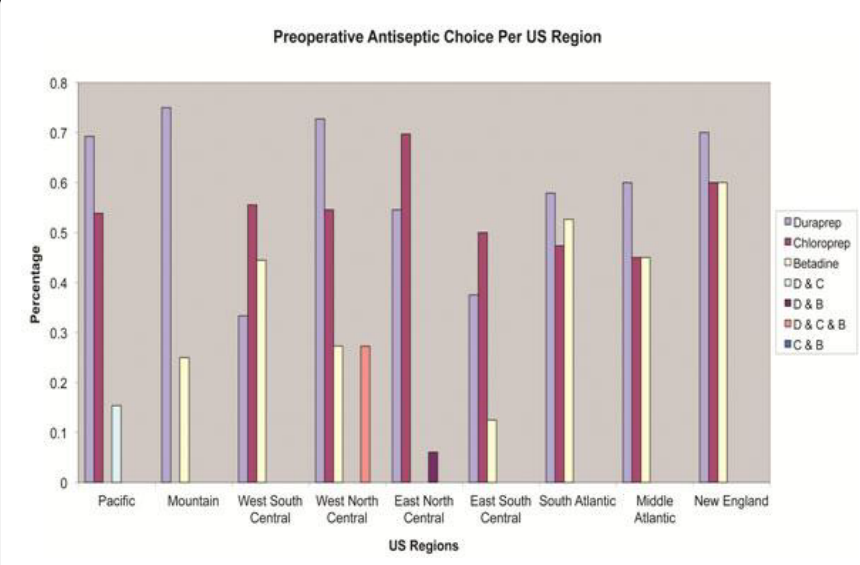

Figure 3: Preoperative Antiseptic Choice per US Region.

New England ( $\mathrm{n}=10,7.93 \%)$. Puerto Rico is not included as a region, though it was surveyed. The preferred antiseptic preparation method by region is represented in Figure 3. ChloraPrep is the preferred choice in 5 regions, whereas DuraPrep is widely used in 3 regions. Only one region, New England, uses different antiseptic solutions, without a particular preference.

\section{Discussion}

SSIs can prolong hospital stay, increase the rate of readmission including to the intensive care unit and increase the potential for death. There is also a significant increase in the overall cost of treatment $[5,8$ 10]. According to the Centers for Disease Control and Prevention (CDC) approximately 290,000 surgical site infections occur annually after general surgical procedures in the United States, representing $22 \%$ of all health-care-associated infections and resulting in $\$ 1$ billion to $\$ 10$ billion in medical costs [11]. In spinal surgery, the incidence of SSIs can be as high as $12 \%$ and can increase the cost of treatment up to 4 -fold [12]

Since the most common pathogens causing SSIs are components of 
normal skin flora which include Staphylococcus aureus and coagulasenegative staphylococci, antiseptic preoperative skin preparation is crucial for prevention of SSIs $[13,14]$. Although Staphylococcus aureus is considered the most frequent $(20-30 \%)$ isolated single pathogen, gram-negative bacteria (Escherichia coli, Klebsiella, Enterobacter, Pseudomonas aureginosa, Proteus) are also reported [3,15]. Most of them $(80-90 \%)$ are superficially located and are the target for antiseptics [16].

Topical antiseptics have been in use for the past 2 centuries. The famous surgeon Joseph Lister first described his experience with carbolic acid as an antisepsis and prophylactic maneuver in 1867. Carbolic acid was originally discovered by Friedlieb Ferdinand Runge in 1834 when he combined, distilled and filtered different acids and base substances [17]. Dr. Lister applied liquid carbolic acid for the treatment of compound fractures as an antiseptic measure. He observed that the application of this chemical substance exercised a local sedative effect, relieving the pain almost immediately while at the same time reacting with the blood, with which it formed a firm mass that hardened into a dense crust that retained the antiseptic property of carbolic acid over a longer period of time [18]. In a later statement, Dr. Lister comments on the use of carbolic acid not only as an antiseptic for washing the wounds after operations, but also for purifying the surrounding skin, the hands of the surgeon, and the instruments [19]. However, in the early stages of the $20^{\text {th }}$ century, no surgeon considered, in comparison with other measures, that antiseptics played more than a minor role in the prevention of infections. [20] Fleming argued against the use of antiseptics to wounds, mentioning that antiseptics result in greater harm. [21,22]. During this period, however, the prevention of infection in wounds using antiseptics was proved convincingly in animal models [23-25]. Afterwards, a considerable number of series investigating the early application of antiseptics indicated that the prophylactic treatment of superficial wounds with antiseptics is justified [23].

The choice between antiseptic skin preparations is debated amongst surgeons. The CDC has recommended using $2 \%$ chlorhexidine-based preparation to clean the site of insertion of vascular catheters, [26] reducing catheter-associated infection by $50 \%$ when compared with povidone-iodine, [27] but this is a much shorter and cleaner procedure than open surgery. To date there have been no guidelines developed for skin preparation to prevent SSIs after open surgery. There are several studies outside the field of spine evaluating methods of skin preparation prior to open surgical procedures. Many surgeons in the United States prefer alcohol based preparations while the majority of European centers continue to use iodine based preparations as a standard of care.

A Cochrane database systematic review performed in 2004 of all antiseptic methods and agents failed to demonstrate priority of any skin antiseptics in open surgery [28]. A more recent meta-analysis published by Lee et al in 2010 searched multiple databases for systematic reviews and randomized controlled trials to compare these two skin preparation approaches [5]. Of the seven eligible studies, the use of chlorhexidine significantly decreased the risk of SSI, compared with the use of iodine. They conclude that although chlorhexidine is more costly than iodine, decreasing the SSIs after its use should reduce the overall costs. One of the limitations to this study was that three large studies contributed to $75 \%$ of the patients outcomes. The first study is from Darouiche et al in 2010, where 409 cases with chlorhexidine-alcohol preoperative skin scrub were compared to 440 cases with povidone-iodine scrub [29]. Surgical site infection rate in clean contaminated cases was significantly lower in the chlorhexidine-alcohol group than in the povidone-iodine group (9.5\% vs. $16.1 \%)$. The other two studies were: Berry et al in 1982 with a total of 453 patients that showed 44 SSIs with chlorhexidine preparation vs. 61 cases with iodine, [30] and the Brown et al study in 1984 that reported 23 SSIs in the chlorhexidine-alcohol group vs. 29 in the iodine group in 378 studied cases [31]. Another recent systematic review from Noorani et al. identified six eligible studies with total 5031 patients and also gave preference to chlorhexidine for SSI prevention [6]. This review evaluated conference proceedings from major surgery meetings, although some studies included in both reviews overlap.

The most recent large study from Switzerland favors povidoneiodine-alcohol skin preparation [32]. They analyzed a total of 1014 skin cultures from 1005 patients and revealed a low rate of SSIs $-4.04 \%$. Low SSIs after iodine skin preparation were also reported by Swenson et al, who studied effects of three preoperative skin preparations on SSIs in 3209 cases, for a 6 month period for each agent [33]. For period one (January 1 - June 30, 2006) they used a povidone-iodine scrub-paint combination (Betadine) with an isopropyl alcohol application between these steps, for period two (July 1, 2006 - December 31, 2007) - 2\% chlorhexidine and 70\% isopropyl alcohol (ChloraPrep), and period three (January 1 - June 30, 2007) - iodine povacrylex in isopropyl alcohol (DuraPrep). Both preparations with iodine revealed lower infection rates compared to ChloraPrep (3.9\% for period three and $6.4 \%$ for period one, compared to 7.1 for period two).

Although there are statistically significant studies in large number of patients that try to identify the best methods for skin preparation in various types of general surgery, there is no unifying conclusion. Skin preparation solutions have not been evaluated in spinal surgery; therefore, as shown in the results of our study, the preferred method for skin preparation is related to the surgeon's predilection. In terms of skin decontamination prior to spine and cranial neurosurgery, there is little data to guide the surgeon. One study from Guzel et al examined growth of skin flora after different skin preparations [34]. While $74 \%$ of initial cultures from the skin grew bacteria, the use of chlorhexidine followed by Betadine administration showed a significant decrease in bacterial growth with $28 \%$ after chlorhexidine administration and to $0 \%$ after the following Betadine application. However, the number of patients in this study was small, and the authors failed to study postoperative infections in those patients.

Each one of the studied antiseptic preparations presents different advantages and disadvantages over the other solutions for skin disinfection in spine surgery. Betadine is a povidone-iodine whose active ingredient is an iodophor. Iodophors are polymerized iodines that make them water soluble, slowly releasing iodine and thus decreasing the risk of skin irritation. Elemental iodine, although it is a potent antiseptic is a strong skin irritant $[35,16]$. Betadine can be used around mucous membranes, the dura, conjunctiva and corneal tissues. It requires a 2 -step scrub and paint application that lasts approximately 2 hours and has excellent coverage against gram positive bacteria and is fairly good against gram negative, fungi, virus and Mycobacterium tuberculosis. [36] Potential disadvantages of iodine-based solutions are the average drying time of 3 minutes and skin irritation and /or an allergic reaction that may occur. Betadine's activity is limited by the amount of time the agent is in contact with the skin and its low overall duration. DuraPrep meanwhile, has a longer duration ( 48 hours), resists wash-off by saline and blood products, and has a better coverage against gram negative and Mycobacterium tuberculosis. An additional feature of DuraPrep is its ability to enhance adhesion between surgical drapes and the prepared skin surface, limiting the spread of organisms onto the surgical field [36,37]. Additionally, alcohol-based solutions (DuraPrep) should not be applied to mucous membranes, and a potential towards flammability exists [34]. There have been a number of reports using alcohol based preps such as DuraPrep and ChloraPrep (see below) in which fires and 
Citation: Kalb S, Lefevre RD, Dididze M, Levi AD (2013) The Use of Anti-Septic Solutions in the Prevention of Neurosurgical Site Infections. Clin Microbial 2: 124. doi: 10.4172/2327-5073.1000124

burns to the skin have occurred after the preps have inadvertently been ignited with electrocautery in cases where full drying was not permitted [38-41]. A recent article describes superficial burns with ChloraPrep use immediately following shoulder arthroscopic surgery [42].

Chlorhexidine has been used in Europe since 1954 and in the United States since 1977. It is composed of a water-soluble, cationic biguanide that binds to the negatively charged bacterial cell wall, resulting in osmotic disequilibrium across the bacterial cell wall at low doses. However, at high doses, chlorhexidine causes precipitation of cytoplasmic contents, denaturizing proteins and causing cell death $[36,43,44]$. Chlorhexidine is not reabsorbed from skin, does not require a waiting time for drying, has immediate onset of action, and provides a broad coverage against gram positive and negative bacteria, facultative anaerobes and aerobes, yeasts, and some lipid-enveloped viruses including HIV [44]. ChloraPrep contains high doses of chlorhexidine (2\%), although recent study from Japan found that $0.5 \%$ chlorhexidine is as effective as $1 \%$ and $2 \%$, based on skin testing on 74 adult volunteers [45]. Potential disadvantages include its flammability and its higher cost compared to iodine [5]. Although chlorhexidine is generally, considered safe, potential and very dangerous complications can occur. Corneal damage due to its toxicity has been reported. In cervical spine cases, leakage of chlorhexidine into the eye can occur. It may be difficult to monitor if the skin disinfectant gets into the eye particularly when the patient is in the prone position during surgery. A few cases of corneal damage have been described resulting in various degree of vision loss up to blindness, some even requiring corneal transplants after the use of chlorhexidine [46]. Additional reported side effects of chlorhexidine include dermatitis, ototoxicity, and hypersensitive reaction with anaphylaxis.

\section{Conclusions}

Our study provides a comprehensive analysis on the preferred skin preparation for spinal surgery amongst the leading neurosurgical departments in the United States. The results show a wide discrepancy in the choice of preparation, concluding that it all comes down to the attending surgeon's preferences. Even though most of the literature is in favor of ChloraPrep over Betadine or DuraPrep in reducing SSI, the majority of neurosurgical departments continue to use iodine solutions in spine procedures.

\section{References}

1. Gerometta A, Rodriguez Olaverri JC, Bitan F (2012) Infections in spinal instrumentation. Int Orthop 36: 457-464.

2. Levi AD, Dickman CA, Sonntag VK (1997) Management of postoperative infections after spinal instrumentation. J Neurosurg 86: 975-980.

3. Pull ter Gunne AF, Cohen DB (2009) Incidence, prevalence, and analysis of risk factors for surgical site infection following adult spinal surgery. Spine (Phila Pa 1976) 34: 1422-1428

4. Schimmel JJ, Horsting PP, de Kleuver M, Wonders G, van Limbeek J (2010) Risk factors for deep surgical site infections after spinal fusion. Eur Spine J 19: $1711-1719$.

5. Lee I, Agarwal RK, Lee BY, Fishman NO, Umscheid CA (2010) Systematic review and cost analysis comparing use of chlorhexidine with use of iodine for preoperative skin antisepsis to prevent surgical site infection. Infect Control Hosp Epidemiol 31: 1219-1229.

6. Noorani A, Rabey N, Walsh SR, Davies RJ (2010) Systematic review and metaanalysis of preoperative antisepsis with chlorhexidine versus povidone-iodine in clean-contaminated surgery. Br J Surg 97: 1614-1620.

7. US Department of Commerce, Economics and Statistics Administration, US Census Bureau, Geography Division.

8. Kurz A, Sessler DI, Lenhardt R (1996) Perioperative normothermia to reduce the incidence of surgical-wound infection and shorten hospitalization. Study of Wound Infection and Temperature Group. N Engl J Med 334: 1209-1215.

9. Mangram AJ, Horan TC, Pearson ML, Silver LC, Jarvis WR (1999) Guideline for prevention of surgical site infection, 1999. Hospital Infection Control Practices Advisory Committee. Infect Control Hosp Epidemiol 20: 250-278.

10. National Institute for Health and Clinical Excellence (NICE) (2006) Surgical site infection: draft full guideline. London, UK: National Institute for Health and Clinical Excellence.

11. American Academy of Orthopaedic Surgeons Patient Safety Committee Evans RP (2009) Surgical site infection prevention and control: an emerging paradigm. J Bone Joint Surg Am 91 Suppl 6: 2-9.

12. Calderone RR, Garland DE, Capen DA, Oster H (1996) Cost of medical care for postoperative spinal infections. Orthop Clin North Am 27: 171-182.

13. Noble W (1986) Skin as a source for hospital infection. Infect Control 7: 111 112

14. van Ek B, Bakker FP, van Dulken H, Dijkmans BA (1986) Infections after craniotomy: a retrospective study. J Infect 12: 105-109.

15. Wenzel RP (2010) Minimizing surgical-site infections. N Engl J Med 362: 75-77.

16. Sebben JE (1983) Surgical antiseptics. J Am Acad Dermatol 9: 759-765.

17. Runge F (1834) Ueber einige Produkte der Steinkohlendestillation, Poggendorffs Annalen der Physik und Chemie 32: 65.

18. Lister J (1867) On a new method of treating compound fractures, abscess etc with observations on the conditions of suppuration. Lancet 1: 326.

19. Lister J (1908) Remarks on some points in the history of antiseptic surgery. Lancet 1: 1815-1816.

20. Russell D, Falconer M (1941) Antiseptics in brain wounds an experimenta study of the histological reaction of cerebral tissues to various antiseptic solutions. Br J Surg, 28: 472-499.

21. Fleming A (1924) Proc Roy. Soc. B, 96, 171.

22. Fleming A: (1931). Brit. Dent. J. 52, 105

23. Gordon J, McLeod JW, Mayr-Harting A, Orr JW, Zinnemann K (1947) The value of antiseptics as prophylactic applications to recent wounds. J Hyg (Lond) 45: 297-306.

24. Schiemann O, Wreschner H (1922). Z. Hyg. InfektKr. 95, 424.

25. Weise K (1922). Z. Hyg. InfektKr. 97, 56

26. O'Grady NP, Alexander M, Dellinger EP, Gerberding JL, Heard SO, et al. (2002) Guidelines for the prevention of intravascular catheter-related infections. Infect Control Hosp Epidemiol 23: 759-769.

27. Chaiyakunapruk N, Veenstra DL, Lipsky BA, Saint S (2002) Chlorhexidine compared with povidone-iodine solution for vascular catheter-site care: a metaanalysis. Ann Intern Med 136: 792-801.

28. Edwards P, Lipp A, Holmes A (2004) Preoperative skin antisepsis for preventing surgical wound infections after clean surgery. Cochrane Database Syst Rev :CD003949

29. Darouiche RO, Wall MJ Jr, Itani KM, Otterson MF, Webb AL, et al. (2010) Chlorhexidine-Alcohol versus Povidone-lodine for Surgical-Site Antisepsis. N Engl J Med 362: 18-26.

30. Berry AR, Watt B, Goldacre MJ, Thomson JW, McNair TJ (1982) A comparison of the use of povidone-iodine and chlorhexidine in the prophylaxis of postoperative wound infection. J Hosp Infect 3: 55-63.

31. Brown TR, Ehrlich CE, Stehman FB, Golichowski AM, Madura JA, et al. (1984)A clinical evaluation of chlorhexidine gluconate spray as compared with iodophor scrub for preoperative skin preparation. Surg Gynecol Obstet 158: 363-366.

32. Tschudin-Sutter S, Frei R, Egli-Gany D, Eckstein F, Valderrabano V, et al (2012) No risk of surgical site infections from residual bacteria after disinfection with povidone-iodine-alcohol in 1014 cases: a prospective observational study. Ann Surg 255: 565-569.

33. Swenson BR, Hedrick TL, Metzger R, Bonatti H, Pruett TL, et al. (2009) Effects of preoperative skin preparation on postoperative wound infection rates: a prospective study of 3 skin preparation protocols. Infect Control Hosp Epidemiol 30: 964-971. 
Citation: Kalb S, Lefevre RD, Dididze M, Levi AD (2013) The Use of Anti-Septic Solutions in the Prevention of Neurosurgical Site Infections. Clin Microbial 2: 124. doi: 10.4172/2327-5073.1000124

Page 5 of 5

34. Guzel A, Ozekinci T, Ozkan U, Celik Y, Ceviz A, et al. (2009) Evaluation of the skin flora after chlorhexidine and povidone-iodine preparation in neurosurgical practice. Surg Neurol 71: 207-210.

35. Choi S, McComb JG, Levy ML, Gonzalez-Gomez I, Bayston R (2003) Use of elemental iodine for shunt infection prophylaxis. Neurosurgery 52: 908-912.

36. Sebben JE (1983) Surgical antiseptics. J Am Acad Dermatol 9: 759-765.

37. [No authors listed] (2003) Improper use of alcohol-based skin preps can cause surgical fires. Health Devices 32: 441-443.

38. Barker SJ, Polson JS (2001) Fire in the operating room: a case report and laboratory study. Anesth Analg 93: 960-965.

39. Briscoe CE, Hill DW, Payne JP (1976) Inflammable antiseptics and theatre fires. Br J Surg 63: 981-983.

40. Prasad R, Quezado Z, St Andre A, O'Grady NP (2006) Fires in the operating room and intensive care unit: awareness is the key to prevention. Anesth Analg 102: $172-174$
41. Sanders TH, Hawken SM (2012) Chlorhexidine burns after shoulder arthroscopy. Am J Orthop (Belle Mead NJ) 41: 172-174.

42. Hemani ML, Lepor H (2009) Skin preparation for the prevention of surgical site infection: which agent is best? Rev Urol 11: 190-195.

43. McDonnell G, Russell AD (1999) Antiseptics and disinfectants: activity, action, and resistance. Clin Microbiol Rev 12: 147-179.

44. Milstone AM, Passaretti CL, Perl TM (2008) Chlorhexidine: expanding the armamentarium for infection control and prevention. Clin Infect Dis 46: 274281.

45. Nishihara Y, Kajiura T, Yokota K, Kobayashi H, Okubo T (2012) A comparative clinical study focusing on the antimicrobial efficacies of chlorhexidine gluconate alcohol for patient skin preparations. J Infus Nurs 35: 44-50.

46. Tabor E, Bostwick DC, Evans CC (1989) Corneal damage due to eye contact with chlorhexidine gluconate. JAMA 261: 557-558. 